\title{
Epidemiological and Immunological Features of Obesity and SARS-CoV-2
}

Eric J. Nilles ${ }^{1,2,3,4, * \mathbb{D}}$, Sameed M. Siddiqui ${ }^{5,6}$, Stephanie Fischinger ${ }^{7}$, Yannic C. Bartsch ${ }^{7}$, Michael de St. Aubin ${ }^{3} \mathbb{D}$, Guohai Zhou ${ }^{1,2}$, Matthew J. Gluck ${ }^{8}$ (D), Samuel Berger ${ }^{8}$, Justin Rhee ${ }^{8}$, Eric Petersen ${ }^{8}$, Benjamin Mormann ${ }^{1,8}$, Michael Loesche ${ }^{1,8} \mathbb{D}^{D}$, Yiyuan $\mathrm{Hu}^{8}$, Zhilin Chen ${ }^{7}$, Jingyou Yu ${ }^{7,9}$, Makda Gebre ${ }^{7,9}$, Caroline Atyeo ${ }^{7}$, Matthew J. Gorman ${ }^{7}$, Alex Lee Zhu ${ }^{7}$, John Burke ${ }^{7}$, Matthew Slein ${ }^{7} \mathbb{D}$, Mohammad A. Hasdianda ${ }^{1,2} \mathbb{D}$, Guruprasad Jambaulikar 1,2, Edward W. Boyer 1,2, Pardis C. Sabeti 4,6,9,10, Dan H. Barouch 6,11, Boris Julg ${ }^{6}$, Adam J. Kucharski ${ }^{12}$, Elon R. Musk ${ }^{8}$, Douglas A. Lauffenburger ${ }^{13}$, Galit Alter ${ }^{4,6,+}$ and Anil S. Menon ${ }^{8,+}$

check for updates

Citation: Nilles, E.J.; Siddiqui, S.M.; Fischinger, S.; Bartsch, Y.C.; de St. Aubin, M.; Zhou, G.; Gluck, M.J.; Berger, S.; Rhee, J.; Petersen, E.; et al. Epidemiological and Immunological Features of Obesity and SARS-CoV-2. Viruses 2021, 13, 2235. https://doi.org/ $10.3390 /$ v13112235

Academic Editor: Eric Piver

Received: 6 October 2021

Accepted: 2 November 2021

Published: 6 November 2021

Publisher's Note: MDPI stays neutral with regard to jurisdictional claims in published maps and institutional affiliations.

Copyright: (c) 2021 by the authors. Licensee MDPI, Basel, Switzerland. This article is an open access article distributed under the terms and conditions of the Creative Commons Attribution (CC BY) license (https:/ / creativecommons.org/licenses/by/ $4.0 /)$.
1 Brigham and Women's Hospital, Boston, MA 02115, USA; gzhou5@bwh.harvard.edu (G.Z.); bmormann@mgh.harvard.edu (B.M.); michael.loesche@mgh.harvard.edu (M.L.); mhasdianda@bwh.harvard.edu (M.A.H.); gjambaulikar@bwh.harvard.edu (G.J.); eboyer@bwh.harvard.edu (E.W.B.)

2 Harvard Medical School, Boston, MA 02115, USA

3 Harvard Humanitarian Initiative, Boston, MA 02114, USA; mdestaubin@hsph.harvard.edu

4 Massachusetts Consortium on Pathogen Readiness, Boston, MA 02115, USA; pardis@broadinstitute.org (P.C.S.); galter@mgh.harvard.edu (G.A.)

5 Computational and Systems Biology Program, Massachusetts Institute of Technology, Cambridge, MA 02139, USA; sameed@mit.edu

6 Broad Institute of MIT and Harvard, Cambridge, MA 02142, USA; dbarouch@bidmc.harvard.edu (D.H.B.); bjulg@mgh.harvard.edu (B.J.)

7 Ragon Institute of MGH, MIT and Harvard, Cambridge, MA 02139, USA; sfischinger@mgh.harvard.edu (S.F.); ybartsch@mgh.harvard.edu (Y.C.B.); zchen30@mgh.harvard.edu (Z.C.); jyu36@mgh.harvard.edu (J.Y.); mgebre@bidmc.harvard.edu (M.G.); catyeo@mgh.harvard.edu (C.A.); mGorman8@mgh.harvard.edu (M.J.G.); ALZHU@mgh.harvard.edu (A.L.Z.); JSBURKE@mgh.harvard.edu (J.B.);

matthew.d.slein.gr@dartmouth.edu (M.S.)

8 Space Exploration Technologies Corp., Hawthorne, CA 90250, USA; mgluck7@gmail.com (M.J.G.); sbeger@email.arizona.edu (S.B.); justin_rhee@brown.edu (J.R.); eric.petersen@ucdenver.edu (E.P.); yiyuan.hu.med@dartmouth.edu (Y.H.); jehn@spacex.com (E.R.M.); anil.menon@spacex.com (A.S.M.)

9 Harvard T.H. Chan School of Public Health, Boston, MA 02115, USA

10 Howard Hughes Medical Institute, Chevy Chase, MD 20815, USA

11 Center for Virology and Vaccine Research, Beth Israel Deaconess Medical Center, Boston, MA 02115, USA

12 London School of Hygiene and Tropical Medicine, London WC1E 7HT, UK; Adam.Kucharski@lshtm.ac.uk

13 Department of Biological Engineering, Massachusetts Institute of Technology, Cambridge, MA 02139, USA; lauffen@mit.edu

* Correspondence: enilles@bwh.harvard.edu

$+\quad$ These authors contributed equally.

Abstract: Obesity is a key correlate of severe SARS-CoV-2 outcomes while the role of obesity on risk of SARS-CoV-2 infection, symptom phenotype, and immune response remain poorly defined. We examined data from a prospective SARS-CoV-2 cohort study to address these questions. Serostatus, body mass index, demographics, comorbidities, and prior COVID-19 compatible symptoms were assessed at baseline and serostatus and symptoms monthly thereafter. SARS-CoV-2 immunoassays included an IgG ELISA targeting the spike RBD, multiarray Luminex targeting 20 viral antigens, pseudovirus neutralization, and T cell ELISPOT assays. Our results from a large prospective SARS$\mathrm{CoV}-2$ cohort study indicate symptom phenotype is strongly influenced by obesity among younger but not older age groups; we did not identify evidence to suggest obese individuals are at higher risk of SARS-CoV-2 infection; and remarkably homogenous immune activity across BMI categories suggests immune protection across these groups may be similar.

Keywords: SARS-CoV-2; COVID-19; body mass index; obesity; epidemiology; clinical features; immunity 


\section{Introduction}

Obesity is a key risk factor for severe disease and death from novel coronavirus disease 2019 (COVID-19) [1,2], the disease caused by severe acute respiratory syndrome coronavirus 2 (SARS-CoV-2). With over 1.9 billion people overweight or obese globally [3], implications for SARS-CoV-2 morbidity and mortality are substantial. After adjusting for age and obesityrelated comorbidities such as diabetes, hypertension, and coronary heart disease, obesity remains a strong independent predictor of excess morbidity and mortality $[1,4,5]$. These findings are not entirely unexpected [6]. Obesity and poor clinical outcomes have been described with other viral pathogens, most notably influenza A (H1N1) during the 2009 pandemic, when obesity was associated with increased hospitalizations, need for intensive care support, and deaths $[7,8]$. In addition to the relationship between obesity and clinical outcomes, emerging evidence suggests a link between higher body mass index (BMI) and higher incidence rates of COVID-19 or SARS-CoV-2 infection [4,9,10], suggesting increased BMI may enhance susceptibility to infection, with important implications for individual-level risks and population-level transmission dynamics [4]. The role of obesity on the immune response to SARS-CoV-2 has also been the focus of intense attention [11]. Obesity has been linked to less robust and/or effective immune response after natural influenza infection [12] or vaccination [13], raising concerns about diminished protective immunity following natural SARS-CoV-2 infection or vaccination $[4,14]$. Yet, results from SARS-CoV-2 vaccine trials suggest similar levels of protection across BMI categories [15]. Thus, given substantial uncertainly about multiple features of obesity and SARS-CoV-2, we investigated if BMI is associated with differential (i) risks of testing positive for anti-SARS-CoV-2 IgG antibodies, (ii) symptom phenotype, and (iii) adaptive immune features.

\section{Materials and Methods}

\subsection{Study Design, Setting and Study Population}

This study examines data from a prospective observational cohort study using serial serological assessment to characterize the immunoepidemiology of SARS-CoV-2 infection among industry employees. Serostatus was unknown at the time of subject enrollment. The study population was comprised of Space Exploration Technologies Corporation employees, all of whom were invited to participate. Study enrollment commenced 20 April and employees were invited to participate on a rolling basis through 28 July 2020; 4469 volunteered and were enrolled from $\sim 8400$ total employees from seven work locations in four US states. Serial blood sampling and interim symptom reporting were performed monthly.

\subsection{Covariates}

Standardized data measures included demographic and medical history variables (listed in Table 1) and COVID-19 compatible symptoms between 1 March 2020, and study enrollment. Symptoms were classified as primary (fever, chills or feverish, cough, anosmia, ageusia) and other compatible symptoms (body or muscle aches, sore throat, nausea or vomiting, diarrhea, congestion, and increased fatigue/generalized weakness). Blood was sampled and interim symptoms were monitored monthly.

\subsection{Laboratory Analyses}

Serological analyses were performed using the Ragon/MGH enzyme-linked immunosorbent assay, which detects IgG against the receptor binding domain (RBD) of the SARS-CoV-2 spike glycoprotein using a previously described method [16] (Appendix A). Assay performance has been externally validated in a blinded fashion at $99.6 \%$ specific and benchmarked against commercial EUA approved assays [17]. Immune profiling methods are detailed in Annex 1. Briefly, specific antibody subclasses and isotypes and Fc $\gamma \mathrm{R}$ binding against SARS-CoV-2 RBD, nucleocapsid and full spike proteins were assessed using a custom Luminex multiplexed assay (Luminex Corp, Austin, TX, USA). Viral neutralization was assessed on a SARS-CoV-2 pseudovirus assay, as described previously [18] with neutralization titer defined as the sample dilution associated with a $50 \%$ reduction 
in luminescent units. The presence of neutralizing activity was defined as a titer $>20$. T cell activity was assessed on an enzyme-linked interferon-gamma immunospot assay with $>25$ spot forming cells per $10^{6}$ peripheral blood mononuclear cells considered positive.

Table 1. Characteristics, serostatus, and unadjusted odds ratios of study participants.

\begin{tabular}{|c|c|c|c|c|c|}
\hline \multirow[t]{2}{*}{ Covariate $^{1}$} & \multirow{2}{*}{$\begin{array}{c}\text { All Participants }(n=4469) \\
\mathrm{N}\end{array}$} & \multicolumn{2}{|c|}{ Seropositive Participants $(n=322)$} & \multirow[t]{2}{*}{ OR $(95 \% \mathrm{CI})$} & \multirow[t]{2}{*}{$p$-Value ${ }^{5}$} \\
\hline & & $\mathbf{N}$ & $\%$ & & \\
\hline \multicolumn{6}{|l|}{ Age group } \\
\hline $18-29 y$ & 1668 & 133 & $8.0 \%$ & ref & \\
\hline $30-39 y$ & 1761 & 104 & $5.9 \%$ & $0.72(0.56$ to 0.94$)$ & $0.0174 *$ \\
\hline $40-49 y$ & 584 & 50 & $8.6 \%$ & $1.08(0.77$ to 1.52$)$ & 0.6545 \\
\hline $50-59 y$ & 315 & 26 & $8.3 \%$ & $1.04(0.67$ to 1.61$)$ & 0.8666 \\
\hline $60+y$ & 85 & 2 & $2.4 \%$ & $0.28(0.07$ to 1.14$)$ & 0.076 \\
\hline \multicolumn{6}{|l|}{ BMI } \\
\hline$<18.5$ & 34 & 3 & $8.8 \%$ & $1.44(0.43$ to 4.80$)$ & 0.5500 \\
\hline $18.5-<25$ & 1686 & 106 & $6.3 \%$ & ref & \\
\hline $25-<30$ & 1523 & 101 & $6.6 \%$ & $1.06(0.80$ to 1.40$)$ & 0.6916 \\
\hline $30-<35$ & 676 & 61 & $9.0 \%$ & $1.48(1.06$ to 2.05$)$ & $0.0196 *$ \\
\hline $35-<40$ & 246 & 23 & $9.3 \%$ & 1.54 (0.96 to 2.47$)$ & 0.0742 \\
\hline$\geq 40$ & 105 & 5 & $4.8 \%$ & 0.75 (0.30 to 1.87$)$ & 0.5308 \\
\hline \multicolumn{6}{|l|}{ Ethnicity } \\
\hline Not Hispanic/Not Latinx & 2492 & 113 & $4.5 \%$ & ref & \\
\hline Hispanic/Latinx & 1274 & 155 & $12.2 \%$ & 2.91 (2.26 to 3.75$)$ & $<0.0001 * * * *$ \\
\hline \multicolumn{6}{|l|}{ Race } \\
\hline White & 2862 & 185 & $6.5 \%$ & ref & \\
\hline $\begin{array}{l}\text { American Indian/Alaska } \\
\text { Native }\end{array}$ & 32 & 3 & $9.4 \%$ & $1.50(0.45$ to 4.96$)$ & 0.5092 \\
\hline Asian & 442 & 18 & $4.1 \%$ & 0.61 (0.37 to 1.01$)$ & 0.0535 \\
\hline Black & 72 & 2 & $2.8 \%$ & $0.41(0.10$ to 1.70$)$ & 0.2207 \\
\hline $\begin{array}{l}\text { Native Hawaiian/Pacific } \\
\text { Islander }\end{array}$ & 29 & 2 & $6.9 \%$ & 1.07 (0.25 to 4.54$)$ & 0.9249 \\
\hline More than one race & 292 & 13 & $4.5 \%$ & $0.67(0.38$ to 1.20$)$ & 0.1796 \\
\hline \multicolumn{6}{|l|}{$\operatorname{Sex}^{2}$} \\
\hline Female & 600 & 40 & $6.7 \%$ & ref & \\
\hline Male & 3730 & 267 & $7.2 \%$ & 1.08 (0.77 to 1.52$)$ & 0.6634 \\
\hline \multicolumn{6}{|c|}{ Children $\leq 18 \mathrm{y}$ in household } \\
\hline No & 3014 & 204 & $6.8 \%$ & ref & \\
\hline Yes & 1342 & 106 & $7.9 \%$ & $1.18(0.93$ to 1.51$)$ & 0.1808 \\
\hline \multicolumn{6}{|l|}{ No. in household } \\
\hline 1 & 640 & 41 & $6.4 \%$ & ref & \\
\hline $2-4$ & 3027 & 214 & $7.1 \%$ & 1.11 (0.79 to 1.57$)$ & 0.5490 \\
\hline$>4$ & 659 & 51 & $7.7 \%$ & 1.23 (0.80 to 1.88$)$ & 0.3499 \\
\hline \multicolumn{6}{|l|}{ Primary work location } \\
\hline Cape Canaveral, Florida & 268 & 17 & $6.3 \%$ & ref & \\
\hline Hawthorne, California & 2859 & 111 & $3.9 \%$ & $0.60(0.35$ to 1.01$)$ & 0.0544 \\
\hline McGregor, Texas & 257 & 21 & $8.2 \%$ & 1.31 (0.68 to 2.55$)$ & 0.4202 \\
\hline Seattle, Washington & 253 & 5 & $2.0 \%$ & 0.30 (0.11 to 0.82$)$ & $0.0190 *$ \\
\hline South Texas, Texas & 712 & 160 & $22.5 \%$ & $4.28(2.54$ to 7.21$)$ & $<0.0001^{* * * *}$ \\
\hline Other & 69 & 1 & $1.4 \%$ & 0.23 (0.03 to 1.79$)$ & 0.1623 \\
\hline
\end{tabular}


Table 1. Cont.

\begin{tabular}{|c|c|c|c|c|c|}
\hline \multirow[t]{2}{*}{ Covariate $^{1}$} & \multirow{2}{*}{$\begin{array}{c}\text { All Participants }(n=4469) \\
\mathrm{N}\end{array}$} & \multicolumn{2}{|c|}{ Seropositive Participants $(n=322)$} & \multirow[t]{2}{*}{ OR $(95 \% \mathrm{CI})$} & \multirow[t]{2}{*}{$p$-Value ${ }^{5}$} \\
\hline & & $\mathbf{N}$ & $\%$ & & \\
\hline \multicolumn{6}{|l|}{ Comorbidities ${ }^{3,4}$} \\
\hline Asthma & 368 & 20 & $5.4 \%$ & $0.72(0.45$ to 1.15$)$ & 0.1721 \\
\hline Hypertension & 356 & 26 & $7.3 \%$ & $1.02(0.67$ to 1.54$)$ & 0.9405 \\
\hline Diabetes mellitus & 101 & 11 & $10.9 \%$ & $1.59(0.84$ to 3.01$)$ & 0.1509 \\
\hline Coronary heart disease & 17 & 1 & $5.9 \%$ & $0.80(0.11$ to 6.08$)$ & 0.8329 \\
\hline Stroke & 9 & 2 & $22.2 \%$ & $3.70(0.76$ to 17.87$)$ & 0.1039 \\
\hline Emphysema/COPD & 9 & 1 & $11.1 \%$ & 1.61 (0.20 to 12.93$)$ & 0.6532 \\
\hline $\begin{array}{c}\text { Cancer-not receiving } \\
\text { treatment }\end{array}$ & 39 & 2 & $5.1 \%$ & $0.69(0.17$ to 2.89$)$ & 0.6163 \\
\hline Other lung disease & 26 & 2 & $7.7 \%$ & $1.07(0.25$ to 4.56$)$ & 0.9233 \\
\hline $\begin{array}{c}\text { Other } \\
\text { immunocompromised }\end{array}$ & 61 & 4 & $6.6 \%$ & 0.92 (0.33 to 2.55$)$ & 0.8710 \\
\hline $\begin{array}{l}\text { Other chronic medical } \\
\text { condition }\end{array}$ & 176 & 9 & $5.1 \%$ & 0.72 (0.36 to 1.43$)$ & 0.3471 \\
\hline \multicolumn{6}{|l|}{ Smoking history } \\
\hline Never & 3769 & 263 & $7.0 \%$ & ref & \\
\hline Prior & 367 & 24 & $6.5 \%$ & 0.93 (0.61 to 1.44$)$ & 0.7514 \\
\hline Current & 229 & 23 & $10.0 \%$ & $1.49(0.95$ to 2.33$)$ & 0.0826 \\
\hline
\end{tabular}

${ }^{1}$ Not reported data: age group ( $\left.n=56\right)$, BMI (199), ethnicity (703), race (740), sex (139), children in HH (113), No. in HH (143), primary location (51), comorbidities (105). ${ }^{2}$ Four (4) reported "other sex", none were seropositive. ${ }^{3}$ For comorbidities reference value for OR is no. COPD chronic obstuctive pulmonary disease. ${ }^{4}$ Other comorbidities with no seropositive participants: chronic kidney disease (10), Heart failure (4), Cancer receiving treatment (3), Other heart disease (22). ${ }^{5} p$-values unadjusted for multiple hypothesis testing: * $<0.05$, $* * * *<0.0001$

\subsection{Data Classification and Analyses}

Seropositivity was determined by the detection of SARS-CoV-2 specific IgG. BMI was calculated by dividing weight in kilograms by height in meters squared and categorized by underweight $\left(<18.5 \mathrm{~kg} / \mathrm{m}^{2}\right)$, normal weight (18.5 to $24 \mathrm{~kg} / \mathrm{m}^{2}$; reference), overweight $\left(25\right.$ to $\left.29 \mathrm{~kg} / \mathrm{m}^{2}\right)$, obesity class $1\left(30\right.$ to $\left.34 \mathrm{~kg} / \mathrm{m}^{2}\right)$, obesity class $2\left(35\right.$ to $\left.39 \mathrm{~kg} / \mathrm{m}^{2}\right)$, and obesity class 3 or severe obesity $\left(\geq 40 \mathrm{~kg} / \mathrm{m}^{2}\right)$ according to the World Health Organization and the US Centers for Disease Control and Prevention.

We performed discrete analyses to address the three aims of the study. For assessment of risk of seropositivity by BMI, the primary exposure of interest was BMI and the outcome variable of interest was seropositivity at any time point. We assessed the unadjusted association between a range of demographic $(n=7)$ and medical history $(n=17)$ covariates using $\chi^{2}$ to compare proportions and ANOVA or Kruskal-Wallis tests to compare means. For adjusted analyses, we constructed a multivariable logistic regression model that included, in addition to BMI and serostatus, age, sex, ethnicity, race, comorbidities, primary work location, number of individuals in the household, and children in the household; variables with a $p$-value $<0.10$ were assessed by backward elimination and excluded if the $p$-value was $>0.10$ and did not meaningfully alter the point estimates of the remaining variables. The risk of being seropositive is expressed as odds ratios (ORs) with binomial exact $95 \%$ confidence intervals (CIs). $p$-values $<0.05$ were considered statistically significant. To understand if obesity status is associated with differential reporting of symptoms, we computed the proportion of seropositive individuals reporting COVID-19 compatible symptoms stratified by obesity status. Symptoms were analyzed from the period preceding the first seropositive result. For example, if an individual was seronegative at baseline and seropositive at the subsequent time point, the symptoms reported between those timepoints were analyzed. The primary exposure of interest was obesity, and symptoms the outcome variables of interest. Given data suggesting the adverse impact of obesity on 
COVID-19 mortality may decline with age [9], we assessed if similar age-dependent obesity risk may be observed for symptom reporting by conducting subgroup analysis stratified by $<$ or $\geq 40$ years, with categorization selected due to sparsity of older participants. Lastly, given an accumulation of evidence that obesity impairs the immune response to a range of pathogens [6,13,19-21], we stratified 20 discrete immune features by obesity status to identify univariate differences.

We additionally performed uniform manifold approximation and projection (UMAP) [22] a mathematical approach for exploratory analyses that constructs a visualizable summary of multiple subjects' characteristics, with each point representing an individual and clusters representing underlying uniformities in subject characteristics. Luminex UMAP and Mann-Whitney U Tests were conducted using scikit-learn, a machine learning toolkit for the Python programming language. Analyses were performed using the R software package (Version 4.0, www.R-project.org/, accessed 1 July 2020) or the Python programming language (Version 3.7, python.org). All available relevant data was included.

\section{Results}

A total of 4469 study participants from $\sim 8400$ total employees (53\%) were enrolled. Baseline characteristics are listed in Table 1. Mean BMI was $27.1 \mathrm{~kg} / \mathrm{m}^{2}$ (SD 5.4) with a median of $25.8 \mathrm{~kg} / \mathrm{m}^{2}$ (range 15.6-60.9). Most subjects were normal weight $\left(18.5-24 \mathrm{~kg} / \mathrm{m}^{2}\right)$ $(1686,39.5 \%)$ or overweight $\left(25-29 \mathrm{~kg} / \mathrm{m}^{2}\right)(1523,35.7 \%)$, and $24.1 \%$ and $0.80 \%$ met criteria for obese $\left(\geq 30 \mathrm{~kg} / \mathrm{m}^{2}\right)$ and underweight $\left(\leq 18.5 \mathrm{~kg} / \mathrm{m}^{2}\right)$, respectively. A total of 322 out of $4469(7.21 \%)$ study participants were seropositive, of which five (1.6\%) were hospitalized and none required critical care support or died. Unadjusted rates are detailed in Table 1 and were higher in South Texas (OR 4.28 [95\% CI, 2.54 to 7.21), $p<0.0001]$ ) and among Hispanics (2.91 [95\% CI 2.26-3.75], $p<0.0001)$; and were lower in Seattle, Washington ( 0.30 [ $95 \% \mathrm{CI}, 0.11$ to 0.82$], p=0.02])$, and in the $30-39$ year age group $(0.72$ [95\% CI, 0.56 to 0.94$], p=0.02)$. Multivariable regression analyses retained only primary work location as significantly associated with serostatus, with increased risk in South Texas (OR 4.28 [2.54-7.21], $p<0.0001$ ) and lower risk in Seattle (OR 0.30 [0.11-0.82], $p=0.02$ ), largely reflecting local transmission rates. The strong univariate association between Hispanic ethnicity and serostatus was not retained after adjusting for work location (OR $1.27[0.94-1.73], p=0.12)$.

\subsection{BMI and Serostatus}

A total of 4270 out of 4469 participants (95.5\%) provided weight and height data and are included in BMI analyses. Unadjusted risks of seropositivity stratified by BMI are listed in the Table 1; only BMI 30 to $34 \mathrm{~kg} / \mathrm{m}^{2}$ (versus normal/healthy weight, $18.5-24 \mathrm{~kg} / \mathrm{m}^{2}$ ) was associated with differential serostatus (OR 1.48 [1.06 to 2.05], $p<0.02$ ). However, after adjusting for all candidate variables (Table 1), no association was detected. Rather, higher BMI and in particular severe obesity (BMI $\geq 40 \mathrm{~kg} / \mathrm{m}^{2}$ ) trended non-significantly to lower seroprevalence (Figure 1A). Subgroup analysis from a single high prevalence location where, given the high force of infection as evidenced by high seroprevalence ( $22.5 \%$ versus $4.2 \%$ for all other sites combined), we predict risks for infection, including any effect of BMI, would be more clearly delineated (Supplementary Materials Table S1). Findings were similar to the primary analysis with no evidence of increased seroprevalence with increasing BMI and point prevalence measures consistently trended lower than normal/healthy weight (Figure 1B). 


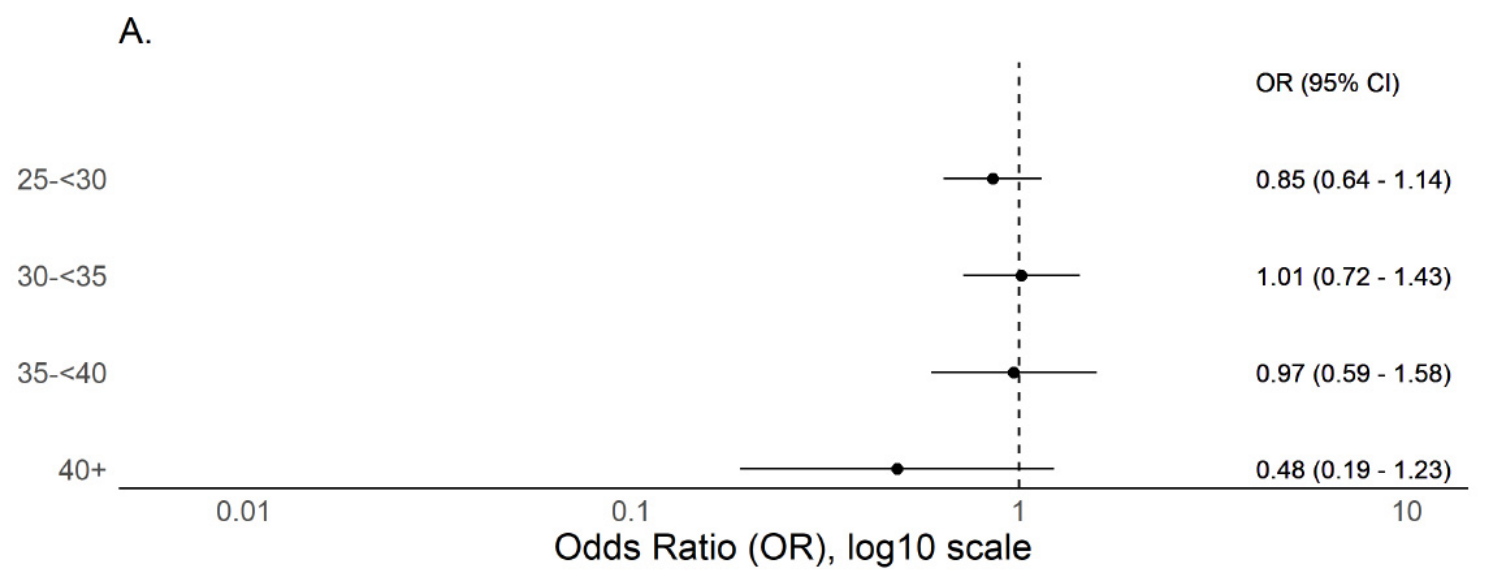

B.

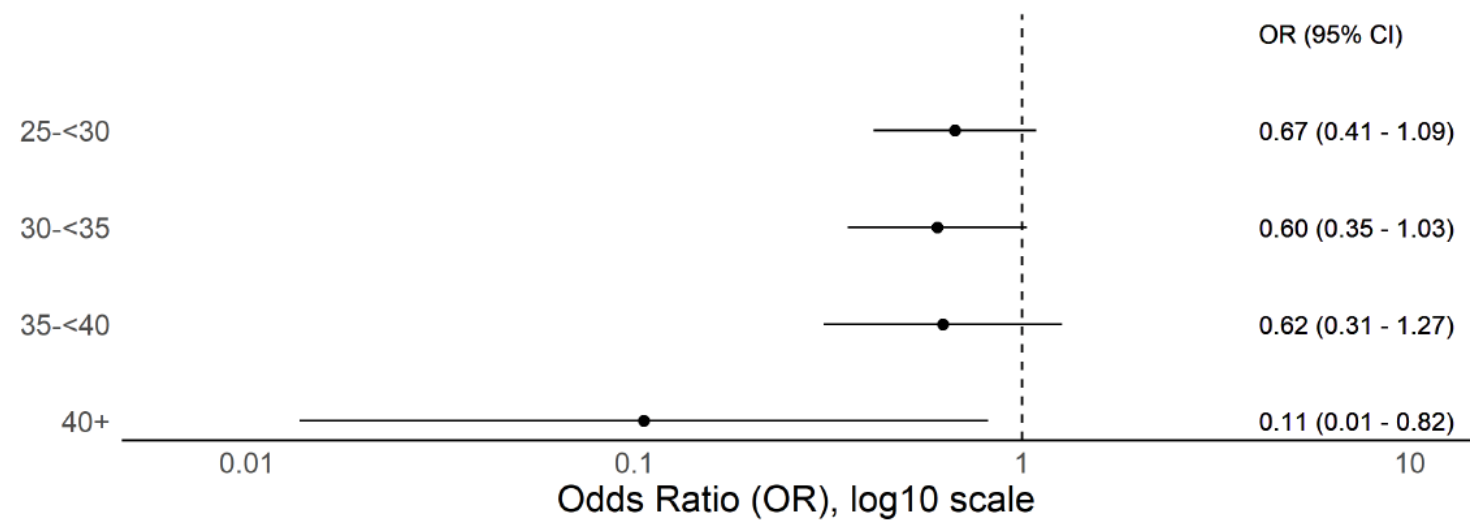

Figure 1. Forest plots of adjusted odds ratio for seropositivity by BMI as a categorical variable with normal BMI (18.5-<25) as reference. (A) Includes participants with BMI measures and demonstrates a non-significant trend to declining seroprevalence with BMI $\geq 40 \mathrm{~kg} / \mathrm{m}^{2}$ when compared to normal/healthy weight (BMI 18.5-24 kg/m²) $(n=4270)$. (B) Includes only participants from a single high seroprevalence (22.5\%) location in South Texas, where the high force of infection may more clearly delineate infection risks $(n=629)$.

\subsection{BMI and COVID-19 Compatible Symptoms}

Of 262 seropositive participants with complete symptom data, three $(1.1 \%)$ were underweight $\left(<18.5 \mathrm{~kg} / \mathrm{m}^{2}\right), 89(34.0 \%)$ normal weight $\left(18.5-24 \mathrm{~kg} / \mathrm{m}^{2}\right), 89(34.0 \%)$ overweight $\left(25-29 \mathrm{~kg} / \mathrm{m}^{2}\right)$, and $81(30.9 \%)$ obese $\left(\geq 30 \mathrm{~kg} / \mathrm{m}^{2}\right)$. A total of $106 / 262(40.5 \%)$ reported one or more of 11 COVID-19- compatible symptoms and 68/262 (26.0\%) reported one or more of five primary COVID-19 symptom. When comparing symptoms between normal weight and overweight (but not obese) individuals, there were no meaningful differences or trends (Supplementary Materials Table S2) and, therefore, subsequent analyses were stratified by obese versus non-obese. Obesity was associated with increased reporting of multiple symptoms including fever, chills or feverish but no measured fever, myalgias, and $\geq 6$ symptoms (Figure 2). Except for congestion (OR 0.87 [0.43-1.70]), a similar and consistent but non-significant trend was observed for all symptoms. Overall, obese individuals registered more symptoms and more primary symptoms. Age appears to play an important role when assessing obesity and symptom phenotype and fever was more commonly reported among obese vs. non-obese individuals under 40 years of age (OR 4.99 [1.97-13.35]) but not over 40 years (OR 1.32 [0.30-5.57]). Similarly, reporting $\geq 6$ symptoms was more common among obese vs. non-obese under 40 years (OR 3.0 [1.32-6.85]) but not for those greater than 40 years (OR 0.94 [0.18-4.26]). A strikingly similar trend was observed for most other symptoms and aggregate symptom measures (Figure 3). To understand if similar age-dependent effects may be observed among younger 
age groups, we performed subgroup analyses on 19-29 versus 30-39 year age groups; no similar age-dependent effects were observed (Figure 4).

\subsection{Obesity and Functional Immune Response}

Among the same 262 seropositive individuals, peak SARS-CoV-2 RBD IgG titers were $0.92 \mathrm{ug} / \mathrm{mL}$ (SD 2.47) among obese $(n=81)$ and $1.12 \mathrm{ug} / \mathrm{mL}$ (SD 3.21) among non-obese $(n=181)$ participants $(p=0.601)$. Deep immune profiling was performed among a subset of 77 participants including 25 obese and 52 non-obese individuals. Mean ELISA NC IgG titers were 0.35 (SD 0.48) among obese versus 0.30 (0.34) among non-obese individuals ( $p=0.57$ ). Viral neutralization activity was detected in $3 / 25(12.0 \%)$ and $6 / 52$ (11.5\%) of obese and nonobese individuals, respectively $(p=0.95)$. When assessing 20 immune features measured by Luminex, no univariate differences were observed between obesity categories, with sparse levels across both obese and non-obese individuals tightly linked to antibody titers (Figure 5A, Supplementary Materials Table S3). Similarly, no clustering or trends between BMI and immunological features were identifiable either by UMAP (Figure 5B) or Spearman's correlation (Figure 5C). Lastly, given evidence that T cells may be key mediators of adaptive immunity in SARS-CoV-2, we examined responses to nucleocapsids protein or spike protein overlapping peptide pools quantified by IFN-g ELISpot among 12 obese and 28 non-obese individuals. There was no difference in the proportion with SARSCoV-2 T cell activity ( $\geq 25$ SFC $/ 10^{6}$ PBMCs) against nucleocapsid peptides (3/12 [25\%] versus $7 / 28[25.0 \%]$ ) or spike peptides (3/12 [25\%] versus $7 / 28$ [25.0\%]). In fact, the only difference observed was higher SFC against nucleocapsid (mean $124 \mathrm{SFC} / 10^{6} \mathrm{PBMCs}$ versus $47 \mathrm{SFC} / 10^{6}$ PBMCs, $p=0.02$ ), but not spike ( $44 \mathrm{SFC} / 10^{6} \mathrm{PBMC}$ sersus $44 \mathrm{SFC} / 10^{6}$ PBMCs, $p=1.00$ ), among obese versus non-obese individuals with $\mathrm{T}$ cell activity.

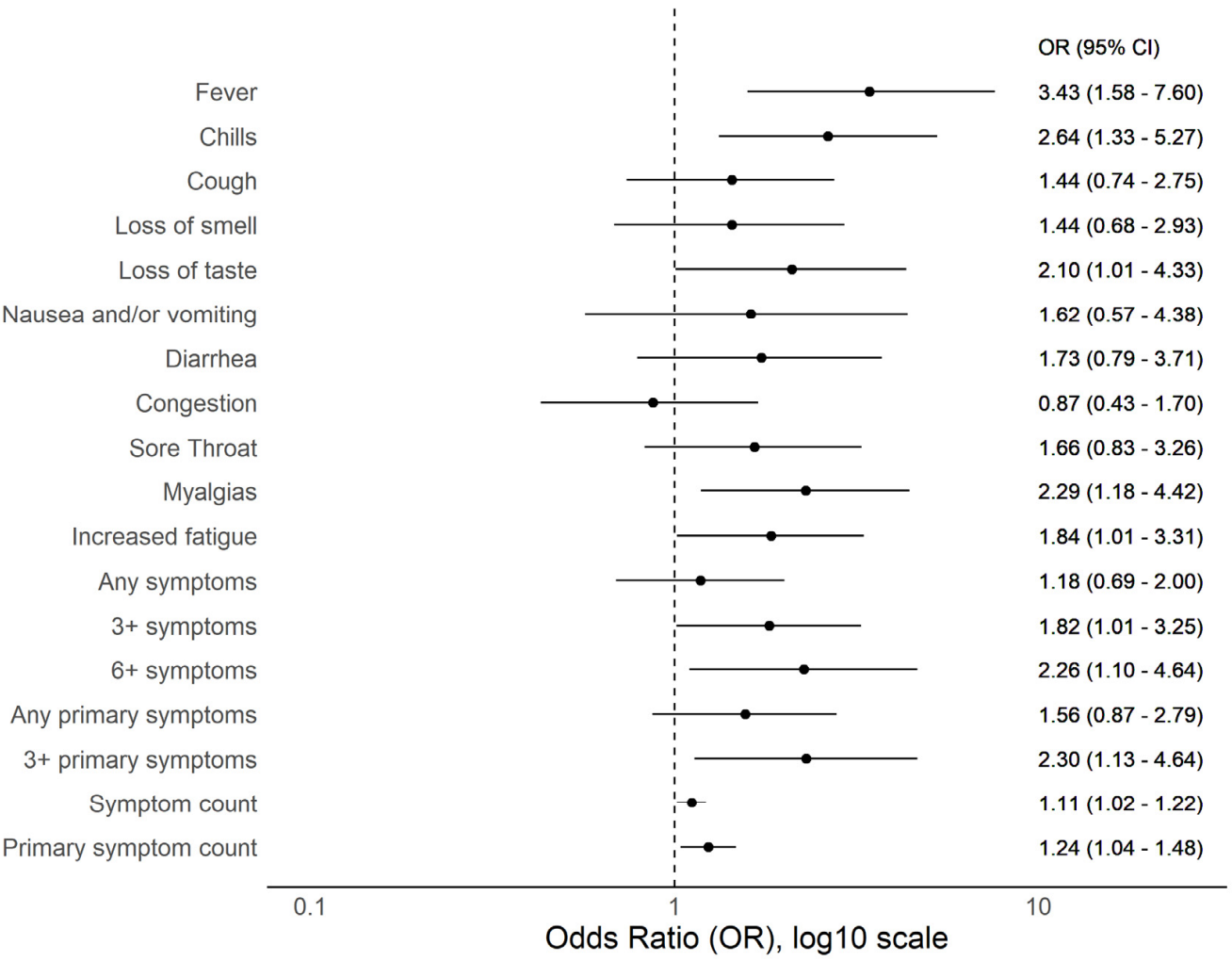

Figure 2. Forest plot of odds ratios of reported COVID-19 compatible symptoms among obese $(n=85)$ versus non-obese $(n=179)$ SARS-CoV-2 seropositive individuals. 
A.

Fever
Chills
Cough
Loss of smell
Loss of taste
Nausea and/or vomiting
Diarriea
Congestion
Sore Throat
Myalgias
Increased fatigue
Any symptoms
$3+$ symptoms
$6+$ symptoms
Any primary symptoms
$3+$ primary symptoms
Symptom count
Primary symptom count

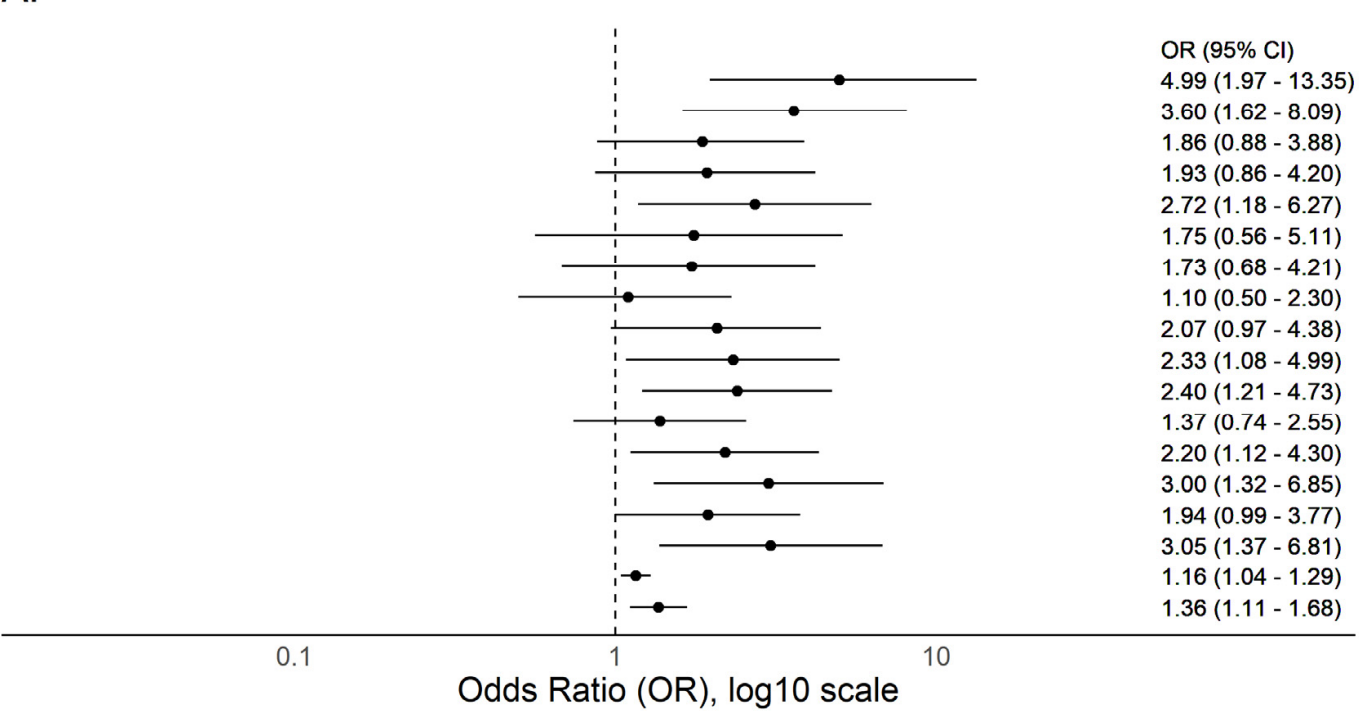

B.

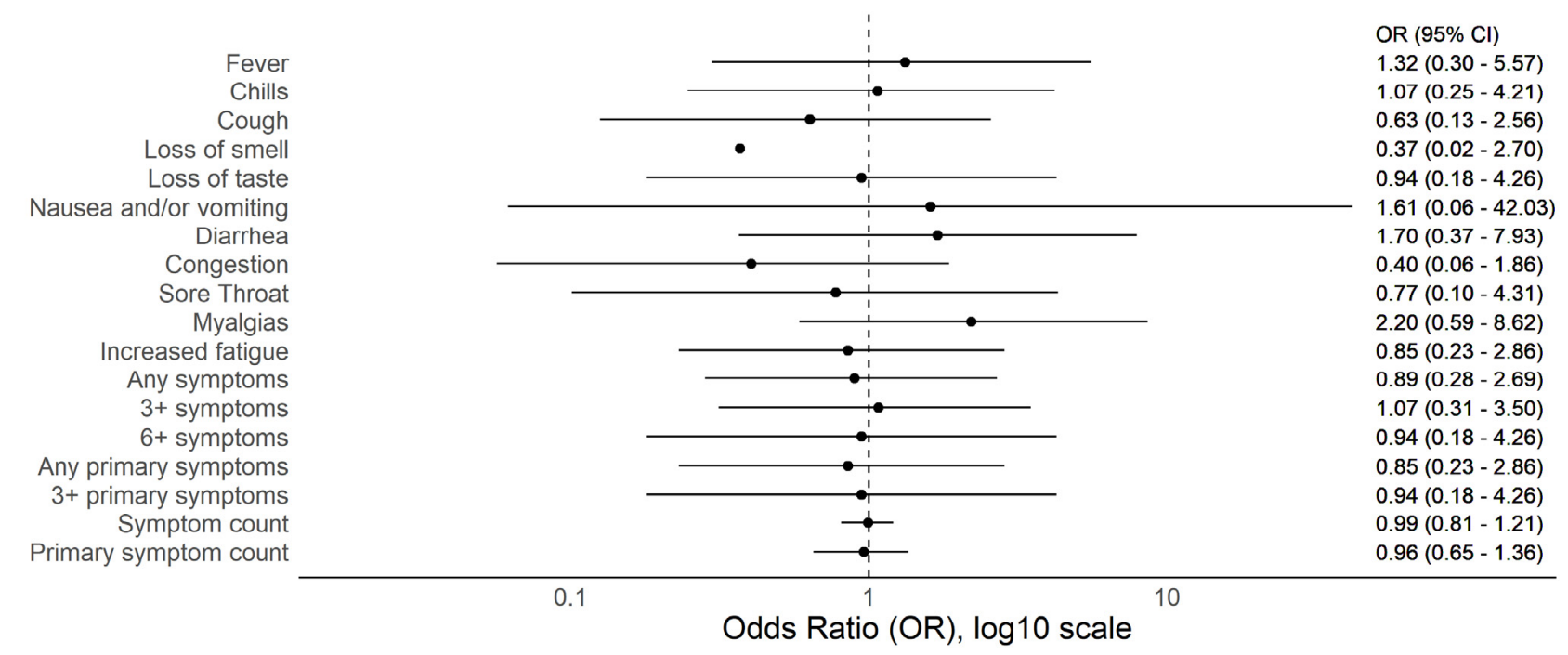

Figure 3. Forest plot of odds ratios of COVID-19 compatible symptoms among obese versus non-obese SARS-CoV-2 seropositive individuals stratified by $(\mathbf{A})<40$ years $(n=195)$ and $(\mathbf{B}) \geq 40$ years $(n=67)$. 
A

\begin{tabular}{|c|c|c|c|c|c|c|}
\hline \multirow{2}{*}{ Symptoms } & \multicolumn{2}{|c|}{$19-29 y$} & \multicolumn{2}{|c|}{$30-39 y$} & \multicolumn{2}{|c|}{$\geq 40 \mathrm{y}$} \\
\hline & $\begin{array}{c}\text { Not obese } \\
88\end{array}$ & $\begin{array}{c}\text { Obese } \\
22\end{array}$ & $\begin{array}{c}\text { Not obese } \\
55\end{array}$ & $\begin{array}{c}\text { Obese } \\
35\end{array}$ & $\begin{array}{c}\text { Not obese } \\
38\end{array}$ & $\begin{array}{c}\text { Obese } \\
24\end{array}$ \\
\hline \multirow{2}{*}{\multicolumn{7}{|c|}{$\begin{array}{l}\text { Fever } \\
\text { Chills }\end{array}$}} \\
\hline & & & & & & \\
\hline Cough & & & & & & \\
\hline \multicolumn{7}{|l|}{ Loss of smell } \\
\hline \multicolumn{7}{|l|}{ Loss of taste } \\
\hline \multicolumn{7}{|l|}{ Nausea or vomiting } \\
\hline \multicolumn{7}{|l|}{ Diarrhea } \\
\hline \multicolumn{7}{|l|}{ Congestion } \\
\hline \multicolumn{7}{|l|}{ Sore throat } \\
\hline \multicolumn{7}{|l|}{ Myalgias } \\
\hline \multicolumn{7}{|l|}{ Increased fatigue } \\
\hline \multicolumn{7}{|l|}{ Any symptoms } \\
\hline \multicolumn{7}{|l|}{$\geq 3$ symptoms } \\
\hline \multicolumn{7}{|l|}{$\geq 6$ symptoms } \\
\hline Any primary symptoms & & & & & & \\
\hline$\geq 3$ primary symptoms & & & & & & \\
\hline
\end{tabular}

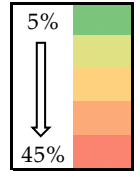

Mean symptom count

Mean primary sx count
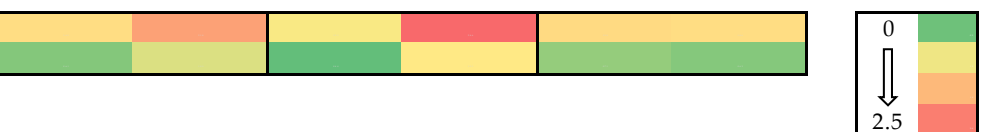

B

\begin{tabular}{|c|c|c|c|c|c|c|}
\hline \multirow[b]{2}{*}{ Symptoms } & \multicolumn{2}{|c|}{$19-29 y$} & \multicolumn{2}{|c|}{$30-39 y$} & \multicolumn{2}{|c|}{$\geq 40 \mathrm{y}$} \\
\hline & $\begin{array}{c}\text { Not obese } \\
88\end{array}$ & $\begin{array}{c}\text { Obese } \\
22\end{array}$ & $\begin{array}{c}\text { Not obese } \\
55\end{array}$ & $\begin{array}{c}\text { Obese } \\
35\end{array}$ & $\begin{array}{c}\text { Not obese } \\
38\end{array}$ & $\begin{array}{c}\text { Obese } \\
24\end{array}$ \\
\hline Fever & $4.5 \%$ & $18.2 \%^{*}$ & $7.3 \%$ & $25.7 \%^{*}$ & $13.2 \%$ & $16.7 \%$ \\
\hline Chills & $10.2 \%$ & $22.7 \%$ & $9.1 \%$ & $31.4 \%^{*}$ & $15.8 \%$ & $16.7 \%$ \\
\hline Cough & $18.2 \%$ & $22.7 \%$ & $12.7 \%$ & $28.6 \%$ & $18.4 \%$ & $12.5 \%$ \\
\hline Loss of smell & $15.9 \%$ & $22.7 \%$ & $9.1 \%$ & $22.9 \%$ & $10.5 \%$ & $4.2 \%$ \\
\hline Loss of taste & $12.5 \%$ & $22.7 \%$ & $5.5 \%$ & $22.9 \%^{*}$ & $13.2 \%$ & $12.5 \%$ \\
\hline Nausea or vomiting & $6.8 \%$ & $4.5 \%$ & $5.5 \%$ & $14.3 \%$ & $2.6 \%$ & $4.2 \%$ \\
\hline Diarrhea & $8.0 \%$ & $22.7 \%^{*}$ & $12.7 \%$ & $11.4 \%$ & $10.5 \%$ & $16.7 \%$ \\
\hline Congestion & $19.3 \%$ & $18.2 \%$ & $20.0 \%$ & $22.9 \%$ & $18.4 \%$ & $8.3 \%$ \\
\hline Sore throat & $15.9 \%$ & $18.2 \%$ & $12.7 \%$ & $31.4 \% *$ & $10.5 \%$ & $8.3 \%$ \\
\hline Myalgias & $13.6 \%$ & $13.6 \%$ & $12.7 \%$ & $34.3 \% *$ & $13.2 \%$ & $25.0 \%$ \\
\hline Increased fatigue & $20.5 \%$ & $31.8 \%$ & $18.2 \%$ & $40.0 \% *$ & $23.7 \%$ & $20.8 \%$ \\
\hline Any symptoms & $39.8 \%$ & $45.5 \%$ & $43.6 \%$ & $51.4 \%$ & $31.6 \%$ & $29.2 \%$ \\
\hline$\geq 3$ symptoms & $23.9 \%$ & $22.7 \%$ & $16.4 \%$ & $45.7 \% *$ & $23.7 \%$ & $25.0 \%$ \\
\hline$\geq 6$ symptoms & $10.2 \%$ & $22.7 \%$ & $9.1 \%$ & $25.7 \%^{*}$ & $13.2 \%$ & $12.5 \%$ \\
\hline Any primary symptoms & $26.1 \%$ & $31.8 \%$ & $18.2 \%$ & $40.0 \%^{*}$ & $23.7 \%$ & $20.8 \%$ \\
\hline$\geq 3$ primary symptoms & $11.4 \%$ & $18.2 \%$ & $9.1 \%$ & $31.4 \%^{*}$ & $13.2 \%$ & $12.5 \%$ \\
\hline Mean symptom count & 1.45 & 2.18 & 1.25 & $2.86^{*}$ & 1.50 & 1.46 \\
\hline Mean primary sx count & 0.61 & 1.09 & 0.44 & $1.31^{*}$ & 0.71 & 0.63 \\
\hline
\end{tabular}

Figure 4. Symptom reporting by age group and obesity status among SARS-CoV-2 seropositive individuals. (A) Heatmap shows consistently higher symptom reporting amongst obese individuals in the 19-29 and 29-39 year age groups but not $\geq 40$-year age group. Number of individuals in each category are listed below obesity markers. (B) Table lists relevant values. ${ }^{*}$ indicates $p<0.05$ for difference between obese and non-obese in that age category with Chi-squared test for proportions and ANOVA for test of mean. 

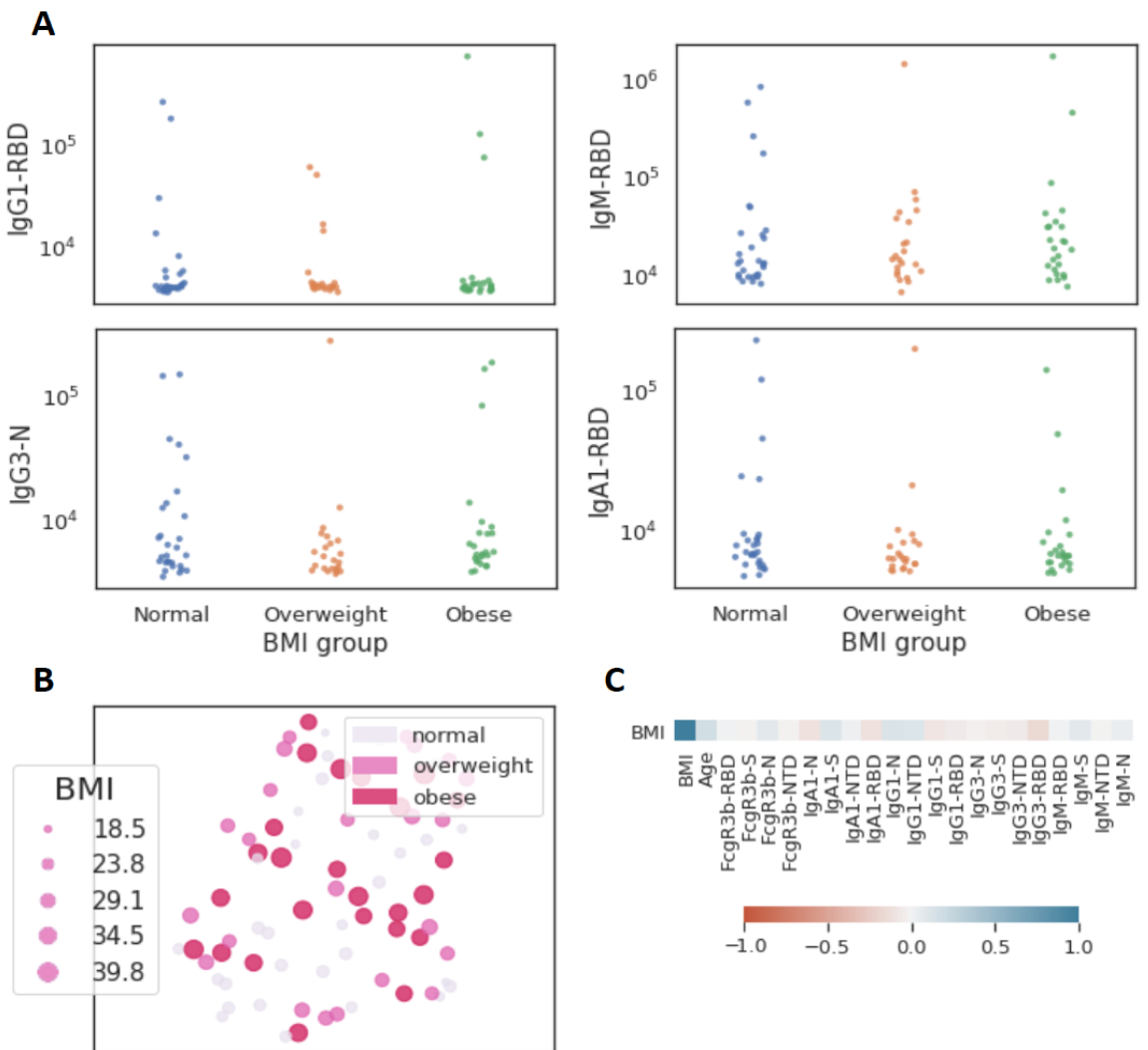

C

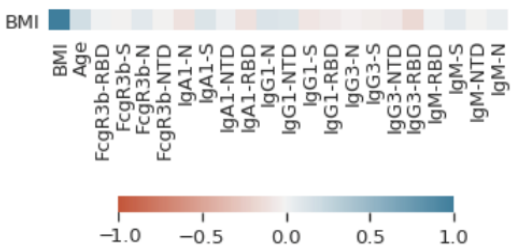

Figure 5. Limited influence of BMI on SARS-CoV-2 antibody profiles $(n=77)$. (A) The dot plots show similar mean fluorescent intensity levels of IgG1, IgM, IgG3, and IgA levels across individuals classified as normal weight $(n=29)$, overweight $(n=23)$, and obese $(n=25)$. (B) The uniform manifold approximation and projection (UMAP) shows the relationship between antibody profiles and BMI (dot size, color intensity), highlighting the limited influence of BMI on shaping SARSCoV-2 antibody responses. (C) Correlation plot of shows limited correlation between BMI and 20 immunological features.

\section{Discussion}

We present data from a multi-site prospective cohort of non-hospitalized individuals unbiased to serostatus at study entry to investigate the association between BMI, SARS-CoV-2 serostatus, symptom phenotype, and functional and non-functional immune measures. Given the prevalence of overweight/obese among adults is close to $70 \%$ in most high-income countries and $\geq 50 \%$, in many lower- and middle-income countries, the scientific and public health implications for the current pandemic are substantial [4]. By combining traditional epidemiological approaches with deep immune profiling, these data provide key insights into the epidemiology and immune characteristics of obesity in SARS-CoV-2 infections.

Studies that report an increased risk of COVID-19 or SARS-CoV-2 infection with higher BMI are intriguing and raise essential questions about factors driving transmission. Given the global burden of obesity, delineating risks for infection is a public health priority. Interestingly, our findings diverge from published reports that examine the risk for COVID19 by BMI, including a nationwide case-control study from South Korea [9] and a crosssectional study from a primary care surveillance network in the United Kingdom [23], that identified an increased risk of COVID-19 with increasing BMI. A meta-analysis of 20 studies reported a pooled increased risk of $46.0 \%(\mathrm{OR}=1.46 ; 95 \% \mathrm{CI}, 1.30-1.65 ; p<0.0001)$ with 18 of 20 studies demonstrating higher COVID-19 risk among obese individuals [4]. Notably, our study did not identify an increase in adjusted seroprevalence with increasing BMI and, conversely, identified a trend to lower infection risk with higher obesity classes. This trend was consistent when both considering all data and when performing subgroup analysis on 
a high transmission site where the increased force of infection may more precisely delineate heterogeneity in infection risks. Reasons for the difference between our and prior study outcomes are likely multifactorial, with differences in study design, obesity classification, and population behaviors likely influencing findings. However, a key difference is we examined SARS-CoV-2 infection risk using serological methods unbiased to exposure risks or presence or absence of symptoms at study entry versus prior studies that examined risks for clinically apparent infection (i.e., COVID-19). As such, our primary outcome measure was SARS-CoV-2 infection rather than clinically apparent disease, a key difference that likely contributes to differences in study findings and conclusions. Given individuals with obesity are more likely to experience fever and multiple other symptoms with SARSCoV-2 infection, as our data indicates, this population is more likely to be tested and over-represented in studies that identify study participants through routine surveillance approaches [24,25].

Our finding that obesity is associated with increased COVID-19 compatible symptoms among SARS-CoV-2 seropositive individuals provides benchmark data for understanding symptom heterogeneity in mild infections by BMI. We demonstrate that not only are well established measures of severe disease such as hospitalization, intensive care requirements and death more common among obese individuals [4,5], but obesity is also an important driver of fever and other symptomatology in non-severe infections. These findings may be due to a dysregulated inflammatory response which is characteristically associated with obesity, that when exposed to a secondary pro-inflammatory inflammatory stimulus, such as during SARS-CoV-2 infection, leads to augmented circulation of pro-inflammatory cytokines. While our data does not define the mechanism driving these findings, it informs our understanding of symptom phenotype and obesity, guides our interpretation of epidemiological data, and highlights potential implications of using passively collected symptom-driven surveillance data to characterize the epidemiology of infectious pathogens. We also identify an intriguing influence of age on obesity and symptom phenotype, with a compelling association below 40 years of age but near complete absence of effect in older adults. These findings are notable given they imply the established interaction between obesity and age on COVID-19 morbidity and mortality, with obesity disproportionately driving increased disease severity among younger age groups $[5,26]$, extend throughout the spectrum of disease and are not restricted to severe disease.

Given the fundamental role of the adaptive immune response in both the resolution of infection and the severity of disease [27], we also probed multiple binding and functional immune markers to assess differential immune responses by obesity status. While previous studies noted poor seroconversion and inadequate seroprotection across vaccine trials targeting other pathogens [28], we did not detect meaningful differences in binding or neutralizing antibodies, T cell activity, or other functional humoral measures by BMI among SARS-CoV-2 infections. These findings, while notable, should be considered in the context of this cohort in which $>98 \%$ of infections were asymptomatic or mild and, therefore, may not capture the full range of disease burden associated with SARS-CoV-2. Yet, the overlapping and indistinguishable antibody and T-cell helper profiles point to unaltered adaptive immunity with BMI, raising the possibility that BMI-driven immunological changes during SARS-CoV-2 infection may manifest largely within the innate immune response. Significant alterations in chronic inflammation, particularly driven by persistent innate cytokine responses from adipocytes including IL-6, TNF- $\alpha$, Type 1 IFN, and Leptin (Figure 6, modified from Alarcon, 2021), have been noted in the setting of obesity [29]. Dissecting the influence of adipocyte inflammatory responses, associated cytokine storm, and enhanced symptomatology, particularly among individuals with a high BMI, may point to mechanistic differences in viral sensing across populations. These data point to remaining knowledge gaps on the relative importance and interplay of the humoral, cellular, and innate immunity in SARS-CoV-2 infection and disease. 


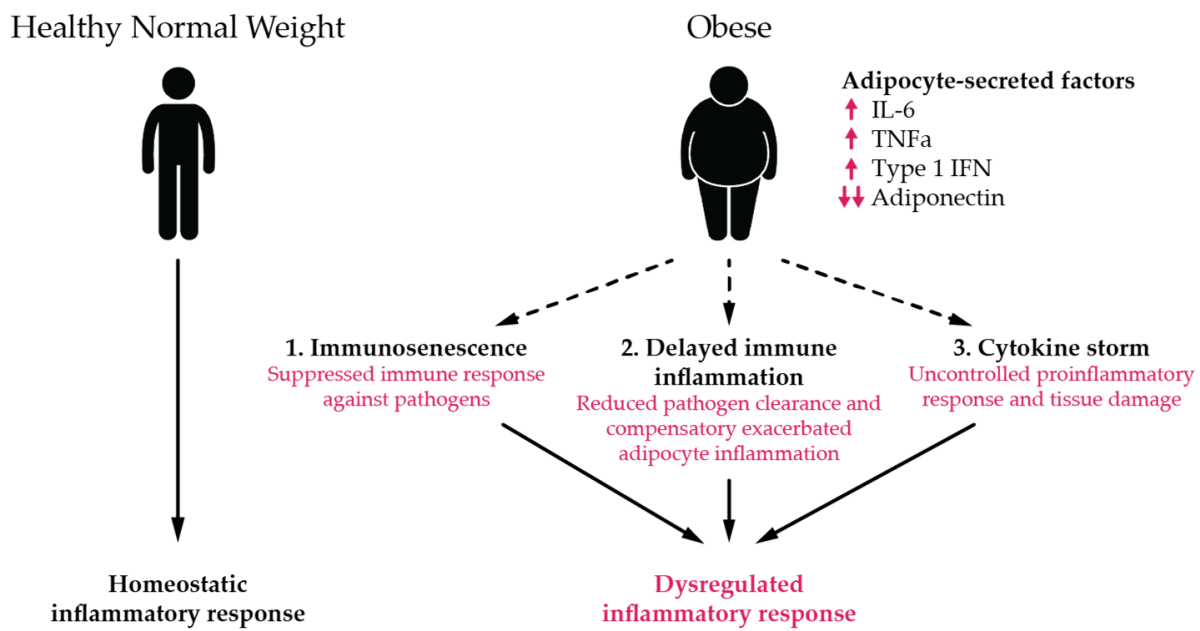

Figure 6. Role of obesity in inflammatory response to infection. Adipocyte-secreted factors (e.g., adiponectin, leptin, Type I IFNs, and IL-6) contribute to normal homeostatic immune responses against infectious pathogens among healthy/normal weight. Obesity-dependent changes in adipocyte function can contribute to (1) immunosenescence (suppressed immune response against pathogens); (2) delayed immune inflammation (reduced pathogen clearance and compensatory exacerbated adipocyte inflammation); and (3) "cytokine storm" (IL-). Modified from Alarcon, 2021 [29].

Although this study is unique in combining a large prospective, multisite serologybased SARS-CoV-2 cohort with deep immune profiling, there are limitations. The study population are industry employees with higher representation of Hispanic ethnicity, white race, male sex, and younger individuals with less comorbidities than the US population; therefore, findings may not be generalizable. Our study enrolled around $50 \%$ of the eligible population, which introduces the potential for ascertainment bias, which may again impact the generalizability of our findings. Given antibody decay can lead to seroreversion (from seropositive to seronegative), some seronegative study participants may have been previously infected. Seroreversion would be expected to occur more frequently among individuals that generated only a weak immune response but given we do not observe a systematic difference between obese and non-obese individuals across multiple immune parameters, including peak anti-RBD IgG titers, we think this is unlikely to meaningfully impact our findings. Other potential study limitations should be noted but their impact would be expected to be evenly distributed across cohort participants and therefore not introduce a systematic bias and impact study findings. These include (i) limited recall of COVID-19 compatible symptoms; (ii) delayed seroconversion relative to reported symptoms, so depending on timing of infection and blood sampling, some registered symptoms may not be due to SARS-CoV-2 infection; and (iii) false positive serological screening results. Lastly, behavioral factors, which can be critical drivers of transmission and may be associated with BMI, were not assessed in this study.

\section{Conclusions}

We demonstrate that obesity influences symptom phenotype in mild COVID-19 infections, suggesting obesity impacts the pathophysiology of COVID-19 throughout the spectrum of disease severity. Our findings do not, however, suggest that obesity increases susceptibility to SARS-CoV-2 infection. Nor did we identify immunological features differentiating obese from non-obese individuals across mild and asymptomatic infection, a hopeful signal that both natural infection- and vaccine-induced protective immunity may be similar across these populations.

Supplementary Materials: The following are available online at https://www.mdpi.com/article/10 $.3390 / v 13112235 /$ s1, Table S1: Characteristics and serostatus of South Texas site with high seropositive rate, Table S2: Symptoms reported by healthy/normal versus overweight but not obese seropos- 
itive individuals, Table S3: Results of univariate differences (Mann-Whitney U test) in immune features by obese versus non-obese status.

Author Contributions: Conceptualization, E.J.N., E.R.M., G.A. and A.S.M.; Data curation, E.J.N., S.F., M.d.S.A., M.J.G. (Matthew J. Gluck), S.B., J.R., M.A.H., G.J. and A.S.M.; Formal analysis, S.M.S., G.Z. and D.A.L.; Funding acquisition, E.J.N., E.R.M., G.A. and A.S.M.; Investigation, S.F., Y.C.B., M.d.S.A., M.J.G. (Matthew J. Gluck), S.B., J.R., E.P., B.M., M.L., Y.H., Z.C., J.Y., M.G., C.A., M.J.G. (Matthew J. Gorman), A.L.Z., J.B., M.S., D.H.B. and B.J.; Methodology, E.J.N., S.M.S., A.J.K., D.A.L., G.A. and A.S.M.; Project administration, E.J.N., G.A. and A.S.M.; Resources, D.H.B., D.A.L., G.A. and A.S.M.; Supervision, E.J.N., E.W.B., P.C.S., D.A.L., G.A. and A.S.M.; Validation, S.M.S., S.F. and Y.C.B.; Visualization, E.J.N., S.M.S. and G.Z.; Writing—original draft, E.J.N.; Writing-review and editing, S.M.S., S.F., M.d.S.A., G.Z., M.J.G. (Matthew J. Gluck), S.B., J.R., E.P., B.M., M.L., Y.H., Z.C., J.Y., M.G., C.A., M.J.G. (Matthew J. Gorman), A.L.Z., J.B., M.S., M.A.H., G.J., E.W.B., P.C.S., D.H.B., B.J., A.J.K., E.R.M., D.A.L., G.A. and A.S.M. All authors have read and agreed to the published version of the manuscript.

Funding: This research was funded through the following sources: the NIH (3R37AI080289-11S1, R01AI146785, U19AI42790-01, U19AI135995-02, U19AI42790-01, 1U01CA260476-01, CIVIC75N93019 C00052); the Gates Foundation Global Health Vaccine Accelerator Platform funding (OPP1146996 and INV-001650); the Musk Foundation; the NASA Translational Research Institute for Space Health (NNX16AO69A); the National Institute for Allergy and Infectious Disease (U19 AI135995); the US Food and Drug Administration (HHSF223201810172C); and the Massachusetts Consortium on Pathogen Readiness (MassCPR).

Institutional Review Board Statement: The study was conducted according to the guidelines of the Declaration of Helsinki and approved by the Western Institutional Review Board (\#20200991, 23 April 2020). The use of de-identified data and biological samples was approved by the Mass General Brigham Healthcare Institutional Review Board (\#2020P001166, 17 April 2020).

Informed Consent Statement: Informed consent was obtained from all subjects involved in the study.

Data Availability Statement: The data presented in this study are available on reasonable request from the corresponding author. The data are not publicly available due to safeguarding employee privacy.

Acknowledgments: We would like to thank Eric Fischer for S protein production efforts and Jared Feldman, Blake Marie Hauser, Tim Caradonna, and Aaron Schmidt for generating receptor binding domain antigen. We thank SpaceX employees Lindsay Chapman, Jordan Steinhart, Suzanne Siebert, and Kyle Meade for their valuable support, in addition to the dedication and commitment of the many SpaceX employees that volunteered to participate in this study.

Conflicts of Interest: G.A. is a founder of Seromyx Systems Inc., a company developing platform technology that describes the antibody immune response. G.A.'s interests were reviewed and are managed by Massachusetts General Hospital in accordance with their conflict-of-interest policies. M.J.G. (Matthew J. Gluck), S.B., Y.H., J.R., E.P., B.M., A.S.M. and E.R.M. are employees of Space Exploration Technologies Corp. All other authors have declared that no conflict of interest exist.

\section{Appendix A}

Serological screening was performed using Ragon/MGH enzyme-linked immunosorbent assay that detects IgG against the receptor binding domain (RBD) of the SARS-CoV-2 spike glycoprotein (provided by Aaron Schmidt) using a previously described method [24]. Briefly, 384-well plates were coated with $0.5 \mu \mathrm{g} / \mathrm{mL}$ of RBD for $1 \mathrm{~h}$ at $37^{\circ} \mathrm{C}$. The plates were then blocked with BSA containing buffer, washed, and plasma samples added at a 1:100 dilution in duplicate for $1 \mathrm{~h}$ at $37^{\circ} \mathrm{C}$, washed, and then detected with a secondary anti-IgG (Bethyl Laboratories). The secondary was washed away after $1 \mathrm{~h}$, and the colorimetric detector was added (Thermo Fisher) for $5 \mathrm{~min}$, the reaction was stopped, and the luminescence was acquired on a luminometer at an absorbance of 450/540 nm. A positive cutoff was equal to the mean of the OD-converted $\mu \mathrm{g} / \mathrm{mL}$ values of the negative control wells on the respective plate plus five times the standard deviation of the concentration from over 100 pre-COVID-19 plasma samples. The background-corrected concentrations 
were divided by the cutoff to generate signal-to-cutoff $(\mathrm{S} / \mathrm{CO})$ ratios. Assay performance has been externally validated in a blinded fashion at $99.6 \%$ specific and benchmarked against commercial EUA approved assays [17].

SARS-CoV2 specific antibody subclass and isotypes and Fc $\gamma \mathrm{R}$ binding were analyzed using a custom Luminex multiplexed assay. SARS2-CoV2-RBD, SARS2-CoV2-N, and SARS2-CoV2-S were coupled to magnetic Luminex beads (Luminex Corp, Austin, TX, USA) by carbodiimide-NHS ester-coupling (Thermo Fisher). Dilution curves were performed on pooled samples from the cohort to determine dilutions in the linear range for each detection reagent. Coupled beads were then incubated with different plasma dilutions (between 1:100 and 1:1000 depending on the secondary reagent) for $2 \mathrm{~h}$ at room temperature in 384-well plates (Greiner Bio-One, Frickenhausen, Germany). Unbound antibodies were washed away and IgG1, IgG3, IgM, or IgA1 were detected with their respective PE-conjugated antibody (all polyclonal, Southern Biotech, Birmingham, AL, USA). For the Fc $\gamma$ R3b binding, a PE-Streptavidin (Agilent Technologies, Santa Clara, CA, USA) coupled recombinant biotinylated human Fc $\gamma$ R3b protein (Duke Protein Production Facility) was used as a secondary probe. After $1 \mathrm{~h}$ incubation, excessive secondary reagent was washed away and the relative antibody concentration per antigen determined on an IQue analyzer (IntelliCyt, Albuquerque, NM, USA). Samples with signals 5-times the standard deviation of the PBS-control well were considered as positive.

The ability of antibodies to neutralize virus was assessed on a 2019-nCoV pseudovirus neutralization assay, as described previously [18]. In brief, HEK293T cells were transfected with pcDNA3.1(-)-hACE2 (Addgene). At $12 \mathrm{~h}$ post transfection, the HEK293T/hACE2 cells were seeded in 96-well plates (2104 cells/well) and incubated overnight. Heat-inactivated $\left(56{ }^{\circ} \mathrm{C}, 30 \mathrm{~min}\right.$ ) plasma samples were serially diluted and mixed with $50 \mu \mathrm{L}$ of pseudoviruses, incubated at $37^{\circ} \mathrm{C}$ for $1 \mathrm{~h}$, and added to the HEK293T/hACE2 cells. Forty-eight hours after infection, cells were lysed in Steady-Glo Luciferase Assay detection (Promega). A standard quantity of cell lysate was used in the luciferase assay with luciferase assay reagent (Promega) according to the manufacturer's protocol. SARS-CoV-2 neutralization titers were defined as the sample dilution at which a 50\% reduction in RLU was observed relative to the average of the virus control wells. The presence of neutralizing activity was defined as a titer $>20$.

PBMCs were isolated and frozen from EDTA blood within $24 \mathrm{~h}$ after collection using Sepmate tubes (Stemcell Technology). PVDV membrane plates (Millipore, MA, USA) were coated with anti-human IFN $\gamma$ antibody (clone: 1-DK1, conc.: $2 \mu \mathrm{g} / \mathrm{mL}$ ) overnight. Previously frozen and overnight rested PBMC samples were counted and $2 \times 105$ PBMCs were added per well with S or N overlapping peptide pools (both Miltenyi, Germany) at $1.25 \mu \mathrm{g} / \mathrm{mL}$ peptide, overnight. Medium alone was used as a negative control. Pools of 23 MHC-I restricted peptides from human cytomegalovirus, Epstein-Barr virus, and influenza virus (CEF, Anaspec Inc., Fremont, CA, USA) and 35 MHC-II restricted peptides from human cytomegalovirus, Epstein-Barr virus, influenza virus, tetanus toxin, and adenovirus 5 (CEFTA, Mabtech Inc., Mariemont, OH, USA) were used as positive controls. IFN $\gamma$ secretion was detected with a biotinylated anti-human IFN $\gamma$ antibody (clone: 7 B6-1) and ALP conjugated-Streptavidin. Spots were developed with 1-Step BCIP/NBT-plus reagent (Mabtech Inc.) for $20 \mathrm{~min}$. Membranes were dried and spots were analyzed and counted on an ImmunoSpot CTL analyzer. T cell activity was assessed as positive for $>25$ SFCs $/ 10^{6}$ PBMCs.

\section{References}

1. Hamer, M.; Gale, C.R.; Kivimäki, M.; Batty, G.D. Overweight, obesity, and risk of hospitalization for COVID-19: A communitybased cohort study of adults in the United Kingdom. Proc. Natl Acad Sci. USA 2020, 117, 21011-21013. [CrossRef] [PubMed]

2. Seidu, S.; Gillies, C.; Zaccardi, F.; Kunutsor, S.K.; Hartmann-Boyce, J.; Yates, T. The impact of obesity on severe disease and mortality in people with SARS-CoV-2: A systematic review and meta-analysis. Endocrinol. Diabetes Metab. 2020, 4, e00176. [CrossRef]

3. WHO. Obesity and Overweight: Fact Sheet; WHO Media Centre: Geneva, Switzerland, 2020; Available online: https://www.who. int/news-room/fact-sheets/detail/obesity-and-overweight (accessed on 2 October 2020). 
4. Popkin, B.M.; Du, S.; Green, W.D.; Beck, M.A.; Algaith, T.; Herbst, C.H.; Alsukait, R.; Alluhidan, M.; Alazemi, N.; Shekar, M. Individuals with obesity and COVID-19: A global perspective on the epidemiology and biological relationships. Obes. Rev. 2020, 21, e13128. [CrossRef] [PubMed]

5. Tartof, S.Y.; Qian, L.; Hong, M.V.; Wei, M.R.; Nadjafi, R.F.; Fischer, H.; Li, M.Z.; Shaw, D.S.F.; Caparosa, M.S.L.; Nau, C.L.; et al. Obesity and Mortality Among Patients Diagnosed With COVID-19: Results From an Integrated Health Care Organization. Ann. Intern. Med. 2020, 173, 773-781. [CrossRef]

6. Falagas, M.E.; Kompoti, M. Obesity and infection. Lancet Infect. Dis. 2006, 6, 438-446. [CrossRef]

7. Kwong, J.C.; Campitelli, M.A.; Rosella, L.C. Obesity and Respiratory Hospitalizations During Influenza Seasons in Ontario, Canada: A Cohort Study. Clin. Infect. Dis. 2011, 53, 413-421. [CrossRef] [PubMed]

8. Centers for Disease Control and Prevention (CDC). Intensive-care patients with severe novel influenza A (H1N1) virus infectionMichigan, June 2009. MMWR Morb. Mortal. Wkly. Rep. 2009, 58, 749-752.

9. Jung, C.-Y.; Park, H.; Kim, D.W.; Lim, H.; Chang, J.H.; Choi, Y.J.; Kim, S.W.; Chang, T.I. Association between Body Mass Index and Risk of COVID-19: A Nationwide Case-Control Study in South Korea. Clin. Infect. Dis. 2020, 73, e1855-e1862. [CrossRef]

10. Ghoneim, S.; Butt, M.U.; Hamid, O.; Shah, A.; Asaad, I. The incidence of COVID-19 in patients with metabolic syndrome and non-alcoholic steatohepatitis: A population-based study. Metab. Open 2020, 8, 100057. [CrossRef]

11. García, L.F. Immune Response, Inflammation, and the Clinical Spectrum of COVID-19. Front. Immunol. 2020, 11, 1441. [CrossRef]

12. Karlsson, E.A.; Sheridan, P.A.; Beck, M.A. Diet-Induced Obesity Impairs the T Cell Memory Response to Influenza Virus Infection. J. Immunol. 2010, 184, 3127-3133. [CrossRef]

13. Neidich, S.D.; Green, W.D.; Rebeles, J.; Karlsson, E.; Schultz-Cherry, S.; Noah, T.L.; Chakladar, S.; Hudgens, M.G.; Weir, S.S.; Beck, M.A. Increased risk of influenza among vaccinated adults who are obese. Int. J. Obes. 2017, 41, 1324-1330. [CrossRef] [PubMed]

14. Wadman, M. Why COVID-19 Is More Deadly in People with Obesity-Even if They're Young. Science. 2020. Available online: https:/ / www.sciencemag.org/news/2020/09/why-covid-19-more-deadly-people-obesity-even-if-theyre-young (accessed on 9 October 2020).

15. Townsend, M.J.; Kyle, T.K.; Stanford, F.C. COVID-19 Vaccination and Obesity: Optimism and Challenges. Obesity 2021, 29, 634-635. [CrossRef]

16. SARS-CoV-2-specific ELISA development. J. Immunol. Methods 2020, 484-485, 112832. [CrossRef]

17. Nilles, E.J.; Karlson, E.W.; Norman, M.; Gilboa, T.; Fischinger, S.; Atyeo, C.; Zhou, G.; Bennett, C.L.; Tolan, N.V.; Oganezova, K.; et al. Evaluation of three commercial and two non-commercial immunoassays for the detection of prior infection to SARS-CoV-2. J. Appl. Lab. Med. 2021, 6, 1561-1570. [CrossRef]

18. Atyeo, C.; Fischinger, S.; Zohar, T.; Slein, M.D.; Burke, J.; Loos, C.; McCulloch, D.J.; Newman, K.L.; Wolf, C.; Yu, J.; et al. Distinct Early Serological Signatures Track with SARS-CoV-2 Survival. Immunity 2020, 53, 524-532.e4. [CrossRef] [PubMed]

19. Milner, J.J.; Sheridan, P.A.; Karlsson, E.; Schultz-Cherry, S.; Shi, Q.; Beck, M.A. Diet-Induced Obese Mice Exhibit Altered Heterologous Immunity during a Secondary 2009 Pandemic H1N1 Infection. J. Immunol. 2013, 191, 2474-2485. [CrossRef]

20. Sheridan, P.A.; Paich, H.A.; Handy, J.; Karlsson, E.; Hudgens, M.G.; Sammon, A.B.; Holland, L.A.; Weir, S.; Noah, T.L.; Beck, M.A. Obesity is associated with impaired immune response to influenza vaccination in humans. Int. J. Obes. 2012, 36, 1072-1077. [CrossRef]

21. Zimmermann, P.; Curtis, N. Factors That Influence the Immune Response to Vaccination. Clin. Microbiol. Rev. 2019, 32, e00084-18. [CrossRef] [PubMed]

22. Becht, E.; McInnes, L.; Healy, J.; Dutertre, C.-A.; Kwok, I.W.H.; Ng, L.G.; Ginhoux, F.; Newell, E.W. Dimensionality reduction for visualizing single-cell data using UMAP. Nat. Biotechnol. 2019, 37, 38-44. [CrossRef]

23. De Lusignan, S.; Dorward, J.; Correa, A.; Jones, N.; Akinyemi, O.; Amirthalingam, G.; Andrews, N.; Byford, R.; Dabrera, G.; Elliot, A.; et al. Risk factors for SARS-CoV-2 among patients in the Oxford Royal College of General Practitioners Research and Surveillance Centre primary care network: A cross-sectional study. Lancet Infect. Dis. 2020, 20, 1034-1042. [CrossRef]

24. Gibbons, C.L.; Mangen, M.-J.J.; Plass, D.; Havelaar, A.H.; Brooke, R.J.; Kramarz, P.; Peterson, K.L.; Stuurman, A.L.; Cassini, A.; Fèvre, E.M.; et al. Measuring underreporting and under-ascertainment in infectious disease datasets: A comparison of methods. BMC Public Health 2014, 14, 147. [CrossRef] [PubMed]

25. Lipsitch, M.; Donnelly, C.; Fraser, C.; Blake, I.; Cori, A.; Dorigatti, I.; Ferguson, N.; Garske, T.; Mills, H.L.; Riley, S.; et al. Potential Biases in Estimating Absolute and Relative Case-Fatality Risks during Outbreaks. PLoS Negl. Trop. Dis. 2015, 9, e0003846. [CrossRef]

26. Kass, D.A.; Duggal, P.; Cingolani, O. Obesity could shift severe COVID-19 disease to younger ages. Lancet 2020, 395, 1544-1545. [CrossRef]

27. Moderbacher, C.R.; Ramirez, S.I.; Dan, J.M.; Grifoni, A.; Hastie, K.M.; Weiskopf, D.; Belanger, S.; Abbott, R.K.; Kim, C.; Choi, J.; et al. Antigen-Specific Adaptive Immunity to SARS-CoV-2 in Acute COVID-19 and Associations with Age and Disease Severity. Cell 2020, 183, 996-1012.e19. [CrossRef] [PubMed]

28. Painter, S.D.; Ovsyannikova, I.G.; Poland, G.A. The weight of obesity on the human immune response to vaccination. Vaccine 2015, 33, 4422-4429. [CrossRef]

29. Alarcon, P.C.; Damen, M.S.; Madan, R.; Deepe, G.S.; Spearman, P.; Way, S.S.; Divanovic, S. Adipocyte inflammation and pathogenesis of viral pneumonias: An overlooked contribution. Mucosal Immunol. 2021, 14, 1224-1234. [CrossRef] 